\title{
Use of Computer Technologies in Education and Scientific Research for Training Economists
}

\author{
Druzhinina O. , Masina O. ${ }^{2} \&$ Vorontsova V. ${ }^{3}$ \\ ${ }^{1}$ Dorodnicyn Computing Center of RAS, Moscow, Russia \\ ${ }^{2}$ Yelets State University Named after I. A. Bunin, Yelets, Russia \\ ${ }^{3}$ Institute of Management, Economics and Finance, Kazan Federal University, Kazan, Russia \\ Correspondence: Druzhinina O., Dorodnicyn Computing Center of RAS, 40, Vavilov st, Moscow, 119333, \\ Russia.
}

Received: December 27, 2014 Accepted: February 19, 2015 Online Published: April 30, 2015

doi:10.5539/ass.v11n11p45 URL: http://dx.doi.org/10.5539/ass.v11n11p45

\begin{abstract}
The paper considers the main directions of computer technology use in education and research for training economists. It describes the main purposes of computer technology application in education. The classification of software in the educational process is presented. It also characterizes main directions of computer technology development for professionals in economics.
\end{abstract}

Keywords: computer technology, educational processes, research in economics

\section{Introduction}

XX-XXI century is marked by the spread of information technology in almost all spheres of human activity, including education (Bordovskiy, 2013; Onokoi, 2012; Fedotova, 2011; Kiselev, 2013). In education, the processes of computerization, internetization, as well as informatization are taking place. As a result of this reformation, the quality, effectiveness and accessibility of education increases. Russian education is characterized by student-centered learning and the development of students' creative abilities, as well as the introduction of information and communication technologies in the training process, the creation of a single interactive educational information space and, finally, the transition to open education.

Improvement of information and communication technologies (creation of local and global networks, databases, and knowledge bases, as well as expert systems) generates specific training information computer area, which enriches the traditional forms of learning.

The rapid development of information and communication technologies allows to realize two main principles of the future education system: the principle of availability and continuity principle. It is information and communication technology that made student-centered education more affordable.

Currently, the world market is highly competitive, and a professional working for economy should be prepared to make decisions in uncertain competitive environment. At the same time, modern conditions require the application of computer technology in education and research when training economists. It is very important to improve the applied content of computer technologies in vocational training of economic universities students. Handling competence of future specialists using computer technologies is not only aimed at the formation of a knowledge system, but also at the professional ability to apply apparatus and methodology of applied mathematics in economics.

Scientific research in the economy is characterized by the following steps: defining the problem; conducting a situation analysis; working out schemes for research; collecting data; presenting information in tables and analysis; construction and study of models; interpreting data and results; report writing; monitoring and verification of the results. At the same time one can use mathematical models which are constructed and studied using probability theory, mathematical statistics, theory of differential equations, optimal control theory, numerical methods, etc. (Dorf \& Bishop, 2008; Bahvalov et al., 2000; Pontryagin et al., 1961; Shestakov, 2007; Druzhinina, 2013). During investigations technologies that provide optimal levels of industry revenues and service rendering, are formed. 
Mathematical models of optimal control which take into account the possible negative impact of the economy on the environment of the region are of theoretical and practical interest (Druzhinina et al., 2010; Druzhinina et al., 2011). Use of computer technology and software to analyze these models is an important component of the study. The study of these models, on the one hand, solves the problem of yield maximization which is produced by an industry of the local economy, and on the other hand, one can search for the conditions which cause minimal damage to the ecology of the region.

The paper (Druzhinina et al., 2010) considers the issues of improving technology of economic sector based on study of dynamic models. The qualitative and numerical study of the model takes into account both the cost-effectiveness and the possible negative impact of the tourism industry on the regional environment. The main methods of study are the methods of optimal control theory and the theory of differential equations. Optimal control model and a model with a hierarchical structure for the economic sectors have also been considered in the works (Druzhinina et al., 2010; Druzhinina et al., 2008).

\section{Main Ways of Using Information Technology in Russian Education}

Currently, the following areas of computer technology in the Russian education and science are being used widely:

1. Computer programs and training systems which include:

- Computer tutorials designed to generate new knowledge and skills;

- Diagnostic or test systems for the diagnosis, evaluation and assessment of knowledge, skills and abilities;

- Simulators and simulation programs, representing some aspect of reality, reflecting its basic structural and functional characteristics and intended for the formation of practical skills;

- Laboratory complexes which are based on simulation programs enabling the learner to use a mathematical model to study a particular reality;

- Expert systems designed to teach the skills of decision-making based on experience accumulated and knowledge;

- Database and knowledge base in different areas that provide access to knowledge;

- Applications and software ensuring the use of specific training operations (processing of texts, drafting tables, graphics editing, etc).

2. Systems based on multimedia technology which are created using video, storage on CD-ROM.

3. Intelligent tutoring expert systems that specialize in specific areas of application and are of practical importance in the learning process, as well as in educational research.

4. Information environment based on databases and knowledge bases, allowing both direct and remote access to information resources.

5. Telecommunication systems that implement e-mail, teleconferencing, etc. and enable access to the global communications network.

6. Electronic desktop publishing office allowing to issue manuals and documents on various media with individual mode at high speed.

7. Digital libraries both of distributed and centralized nature enabling students to implement a new access to global information resources.

8. Geographic information systems which are based on the technology of combining computer mapping and database management systems. As a result, it is possible to create multi-layered electronic maps, the reference layer of which describes the basic phenomenon or situation, and each subsequent one specifies an aspect, process or phenomenon.

9. Information security systems of different orientations (from unauthorized access during storage, from distortions when transmitting, from eavesdropping, etc.).

When creating computer-based training tools a variety of basic information technology can be used. New opportunities offered by modern technologies in education can be illustrated by the example of multimedia technologies. Now you can create textbooks, manuals and other training materials on the data medium. They may be divided into the following groups:

1. Textbooks representing textual exposition with a large number of pictures that can be installed on the server and transmitted via a network to a home computer. With a limited amount of material such textbook can be available through direct access of a user to the server. 
2. Tutorials with highly dynamic illustrations made on CD-ROM. Along with the basic material, they comprise means for interactive access, animation, and video images showing the dynamics of the principles and implementation methods of the individual processes and phenomena. Such books may have not only educational, but also an artistic purpose. Huge storage space of the data media allows you to place encyclopedia, directory, guide, etc on a single optical disc.

3. Modern computer training systems for teaching and research. They implement simulation of both processes and phenomena, i.e. create a new educational computer environment where the student is an active participant and can manage learning process.

4 Virtual reality systems in which the student becomes a participant in a computer model that shows the world. For proper use of multimedia products of this type it is extremely important to study their psychological characteristics and negative impacts on the student.

5 Distance Learning Systems. In difficult socio-economic conditions distance learning becomes especially important for remote regions, for people with low mobility, as well as for self-education and independent work of students. Effective implementation of distance learning is possible only when there is a targeted program to create high-quality multimedia products for educational purposes in the basic, natural sciences, general professional and special disciplines.

\section{Pedagogical Goals of Information Technology}

Informatization transformed largely the process of acquiring knowledge. New training technologies make the educational process more intense, increase the speed of perception, understanding and, more importantly, the depth of acquisition of a large amount of knowledge. In computer technology of training there are two components that are used to transmit educational information:

- Technical equipment: computer equipment and communication tools;

- Software for various purposes.

For planning a lesson with the use of a computer a teacher should know functionality and applicability of each of these components. Both hardware and software have their own characteristics and specific influence on the learning process.

Pedagogical purposes of application of information technologies are:

- Personality development, that is, development of thinking, aesthetic education, the development of experimental research skills, the formation of information culture.

- The execution of social control: the user's general information training (the so-called "computer literacy"), training a specialist in any field;

- Intensifying educational process, which involves improving the efficiency and quality of education, ensuring motivation for cognitive activity, deepening interdisciplinary links through the integration of information and subject training.

\section{Methodological Resources of Information Technology}

Methodological resources of computer technology in education include:

- knowledge visualization;

- individualization, differentiation of teaching;

- the opportunity to trace the development of the object, making a drawing, sequence of operations (computer demonstration);

- Modeling objects, processes and phenomena;

- The development and use of databases;

- Access to a wealth of information, presented in an entertaining way through the use of multimedia;

- Development of skills to process information when working with computer catalogs and directories;

- Possibility of self-control;

- Possibility for training and self-study;

- Reinforcement of learning motivation (through games, multimedia);

- Formation of skills to make the best decision in a difficult situation; 
- Development of a certain kind of thinking (e.g., visual-figurative);

- Creation of learning culture;

- Formation of information culture;

- Saving training time.

\section{Classification of Educational Software}

Computer technology training involves the use of computer technology along with specialized software. Software for educational purposes is a tool which recreates some domain area where technology of its study is realized, the conditions for various learning activities are created. Such software supporting various kinds of functional training processes has been called educational software.

Currently, there are many different classifications and typologies of educational software.

For the methodological purpose, educational software may be:

- Computer tutorials (lessons);

- Software simulators (tutors);

- Controlling (tests);

- Information and referral (encyclopedias);

- Simulating;

- Modeling;

- Demonstration (slide- or video-films);

- Educational game;

- Leisure (computer games: arcade, quests, strategy, role-playing, puzzle, sports, and others types).

\section{Information Systems and the Application of Computer Technology in Professional Activities}

In modern education of future economists use of computer technology is a critical component and one of the basic directions. The development of information and computer technology is an objective necessity:

- First, for training specialists in economics,

- Secondly, to use as a source of auxiliary teaching material (background, training, editing, and so on).

For many subjects studied by specialists in economics, computer is a valuable source of bibliographic and encyclopedic information. Detail designs with computer presentations are widespread, they allow to more clearly present the illustrative material.

Thus, during the course "Mathematical Models in Economics" students-economists effectively use DBMS, a database management system, as well as problem-oriented software packages, programs for financial analysis, banking automation software, small business automation software, organization management automation program. When doing course in "Modern information technologies in economic science and practice" by Master's degree students, attention is paid both to theoretical aspects of computer technology and to practical development of technologies to solve various economic problems. For this purpose, during laboratory research students do exercises including various typical software elements, in particular, Matlab, the processing system of computer mathematics. When doing a course in "Automated information technology in the economy" by bachelor's degree students, to process and analyze economic information spreadsheet program Excel is used, which has a large number of built-in functions for mathematical, statistical, financial and other calculations. Computer technologies used make it easier to work with data and provide results without hand calculating or special programming.

Today, another, important and actual direction in teaching computer technology is the use of internet technology. The purpose of this educational trend is optimization of traditional teaching methods with the use of modern information technology. Modern computer telecommunications provide a variety of educational information, simplify its search, make it more accessible, and present it in the original form. This is what distinguishes the modern computer technologies from traditional learning tools. Modern computer technologies including the Internet involve the development and introduction of innovative methodological approaches to the training system as a whole. 
When using the Internet presentation of material is caused mainly by specific type of classes, course content, and the role of the teacher. For example:

- Support with audio;

- Use of additional materials (articles, academic journals published on the Internet, and so on)

- Use of library resources on the Internet;

- Assignment on the topic in the form of a test, analysis of texts, abstract;

- Forums (seminars) organized on topics given by teacher.

Development and introduction in the educational process of such information resources, including the Internet, greatly expands the boundaries of learning, making it more efficient and diverse. It is equally possible for both full-time and part-time learning.

\section{Conclusion}

Resources of computer technologies will improve the effectiveness of training specialists in economics. Development of computer technology in training future economists is promising, relevant and objectively necessary. In modern Russian education of future economists the use of computer technology is a critical component and one of basic directions. Based on the software classification and uses of information technology in the educational process presented in the paper it may be possible to propose further use of computer technology when studying economic disciplines.

\section{References}

Druzhinina, O. V., Kazakova, I. E., Pershina, E. S., \& Daragan, S. V. (2010). Advances in technology in the tourism sector of the economy on the basis of mathematical simulation. High Tech, 11(3), 58-66.

Druzhinina, O. V., Kazakova, I. E., Pershina, E. S., \& Korzhavina, N. V. (2011). Construction of models of hierarchical control systems in tourism industry taking into account the factor of environmental safety. Scientific Bulletin of MSITI, (3), 14-20.

Druzhinina, O. V., Shulimanova, Z. L., Masina, O. N., Sadykova, O. I., Kuzmina, T. I., \& Ilyina, T. A. (2008). Stability of nonlinear dynamic processes in ecology and physics. RGOTUPS, Moscow.

\section{Copyrights}

Copyright for this article is retained by the author(s), with first publication rights granted to the journal.

This is an open-access article distributed under the terms and conditions of the Creative Commons Attribution license (http://creativecommons.org/licenses/by/3.0/). 